The Stockholm University Linnaeus Center for Integration Studies (SULCIS)

\title{
Ethnic Environment during Childhood and the Educational Attainment of Immigrant Children in Sweden
}

Magnus Bygren and Ryszard Szulkin

Working Paper 2007:8

ISSN 1654-1189 


\title{
Ethnic environment during childhood and the educational attainment of immigrant children in Sweden
}

\author{
Magnus Bygren \\ Department of Sociology \\ Stockholm University \\ Ryszard Szulkin \\ Department of Sociology \\ Stockholm University
}

\begin{abstract}
We ask whether growing up with persons of the same national background (which we refer to as coethnics), in the immediate neighbourhood, influences future educational careers of children of immigrants. We use administrative data to follow an entire cohort of immigrant children who graduated from Swedish compulsory schools in 1995. We have information on their parents and on their ethnic environment during the period they were $10-15$ years old. The dependent variable studied is the highest completed education in years at age 24 . We are able to account for unobserved heterogeneity with neighbourhood fixed effects and ethnic group fixed effects. We find that the effect of the quantitative side of the ethnic environment (the number of coethnics) on educational attainment is strongly conditioned by the qualitative side of this environment (the educational success of coethnics). The individual's educational career is positively related to the number of young coethnics in the neighbourhood, but only if they can be characterized as being educationally successful. Growing up in a large ethnic community with average or poor educational success is harmful for the future educational success. The effect of the ethnic surrounding on the highest completed education is fully mediated by success in compulsory school.
\end{abstract}




\section{INTRODUCTION}

During the 1990's Sweden witnessed a significantly increased immigration as well as an increased ethnic residential segregation (Biterman \& Franzén 2007). Together, these two processes have changed the ethnic composition of the local social spaces in which children of immigrants spend most of their time during their most formative years. The purpose of this paper is to analyse whether and how this kind of spatial segregation during childhood influences the educational careers of individuals with an immigrant background. ${ }^{1}$ Our intention is to go beyond the simple question whether ethnic enclaves are good or bad. A priori, it is hard to tell whether sharing one's immediate social environment with persons of the same ethnic origin is positive or negative. The various characteristics of the social environment must first be discerned before hypotheses about the effects of the environment can be formulated (Cutler et al. 2007). When the ethnic environment encompasses a high proportion of individuals with advantageous social backgrounds, positive effects of social interaction between these individuals can be expected. Children in such a resource-strong environment can be assumed to perform better than children with a similar social background but without access to an environment of such a nature. Inversely, when the ethnic environment consists of a large proportion of individuals from less favourable social circumstances, negative effects of the social interaction may arise. The emergence of this type of interactional effect may imply that individual social backgrounds and the ethnic surroundings interplay in a process where the correlation between origin, school results, and educational career is passed along to new generations.

\section{The pros and cons of the ethnic enclave}

The social science literature on the fortunes of immigrants in their host countries has long been dominated by the "assimilation perspective". Proponents of this perspective

\footnotetext{
${ }^{1}$ We use the concept of "ethnicity" to designate the individual's or his/her parents' country of birth. Naturally, we are aware that persons with the same national origin may belong to different ethnic groups. For example, individuals with their roots in Turkey may be Kurds, Assyrians, or ethnic Turks.
} 
have traditionally emphasised the importance and desirability of the process resulting in the gradual, but preferably speedy, fusion of immigrants into their new environment and becoming "like everyone else" (see Gordon 1964; Chiswick 1978; and Zhou 1997 for a review of the literature). According to the assimilation perspective, there are considerable disadvantages associated with residential segregation. The spatial segregation of immigrants and their children from the majority is, naturally, accompanied by a lack of contacts with members of the host society. Segregation also often means that many immigrants live in areas that are characterized by substantial social problems. Such areas can be assumed to be places where social marginalization is transferred between generations and becomes permanent. In other words, residential segregation can produce obstacles to the accumulation of the knowledge and skills necessary for success in adult life.

The combination of increased immigration and ethnic segregation has altered the ethnic composition of the local social arenas where immigrant youths spend their most formative years. Ethnic segregation is a reality in those industrial countries which have admitted large numbers of immigrants. There is considerable evidence indicating that the assimilation perspective is based more on wishful thinking than on an analysis of segregation tendencies in society. ${ }^{2}$ Many immigrant groups are determined to retain their cultural uniqueness along with strong bonds to their country of origin (Portes 1995). More recent research indicates that belonging to an ethnic minority which forms an ethnic enclave may have both advantages and disadvantages. Concepts such as "ethnic capital" and "quality of the ethnic environment" (Borjas 1992, 1995) are used to illustrate the fact that youths originating from countries with strong educational traditions may benefit by close contacts with other people from their country of origin after emigrating. For welleducated and numerically large minorities, ethnic residential segregation may

\footnotetext{
${ }^{2}$ American researchers ask the following question as well: assimilation to what? Children of non-white immigrants may lack channels for being assimilated into the society's better-off segments. Contacts with native-born persons who also reside in disadvantaged neighborhoods may instead cement norms and cultures of exclusion (Portes 1995; Zhou 1997).
} 
facilitate frequent contacts with their own group and thereby contribute to the preservation of educational traditions (Zhou 1997). Two assumptions underlie the belief that the ethnic surroundings may have an influence on students' school results and educational careers. Firstly, the social environment has an impact on educational success. Secondly, coethnicity facilitates in-group contacts. Both these assumptions are supported by sociological research.

The role of the environment for students' school results, and educational careers is due to the fact that the close social environment is an important sources of norms, role models, and information (for example, see Coleman 1988). The neighbourhood and the school are central places for the formation of peer groups in which individual members have a reciprocal influence on each other's study habits and aspirational levels with regard to school results and educational careers. When a large proportion of members in the peer group regard high educational ambition levels as self-evident, the probability is relatively great that these aspirations will be diffused throughout the group. Inversely, in a peer group where the norms prohibit being a "nerd", a negative attitude towards achievement in school may become dominant. The basic idea here is that aspirations and behaviour are formed in interplay between individuals and their social environment. If we think of school performance and educational career as reflecting individual capacity and individual efforts, social norms and role models may exert a strong influence on effort. Thereby, the peer group, or the social network to which young people belong, may influence their educational performance. The social environment as a source of information may also be of importance for the educational career by means of influencing the choice of school, study programme, etc., which through path-dependency may have long-term consequences for the future educational career of children.

Research on social networks has shown that demographic and social factors such as ethnicity, gender, and age are important for the formation of social bonds, or in-group contacts, as well as for the location of the individuals (centrally or peripherally) within a network (McPherson et al. 2001). In accordance with the so- 
called "similarity attraction" paradigm (Byrne 1971), close relations are primarily formed between individuals with similar social characteristics. Social similarity functions as a mechanism that facilitates communication, reduces uncertainty, and creates trust and reciprocity in the social life (Lincoln and Miller, 1979; McPherson and Smith-Lovin, 1987, Pfeffer 1989; Reskin et al. 1999). There are reasons to believe that similar ethnic backgrounds may be an important factor in the formation of peer groups in neighbourhoods. Empirical studies conducted in the U.S.A. have shown strong ethnic networks to be prevalent among school youngsters (Portes 1995; Zhou and Bankston 1998). Young people often say that their closest friends belong to their ethnic group. Moreover, close contacts within one's ethnic group has been found to have a positive effect on school performance (Portes 1995). To our knowledge there are no corresponding studies that have been conducted in Sweden. The mechanisms that have been analysed in the above-mentioned studies ought, though, to be of a general nature and the discussion applicable to the Sweden context.

An important characteristic of groups formed by similars may be what Coleman (1988) referred to as "intergenerational closure". In social groups where individuals from different generations are acquainted with one another and feel a strong sense of community, the social relations are affected by the high density of the network. These so-called "closed" networks may be especially effective in upholding respect for mutual norms. According to Coleman, in a situation where many parents know the parents of other children living in the same neighbourhood, or when these children attend the same schools as their own children, norms dictating diligence and perseverance - and thereby the students' school performance, and educational careers - may be encouraged (Morgan \& Sørensen 1999). The expectation that ethnic groups have a relatively high degree of "intergenerational closure" is based on the fact that there is a high probability that people with the same country of origin who live close together, and who often have emigrated for similar reasons, know each other and each others' children and maintain strong bonds. Based on such a discussion, there is reason to expect that ethnicity-based peer groups in the neighbourhoods will be 
characterised by a high degree of solidarity, and that this group affiliation will influence, inter alia, the educational performance of the young people.

The point of departure for the present empirical analysis is thus that the social interaction between individuals of the same ethnic background, who live in the same neighbourhood, is relatively strong and that these relations influence the school performance, educational choices, and consequently the future educational career of children growing up there. Such network mechanisms may self-reinforce norms and behaviors and have been found to influence, inter alia, the accumulation of human capital, the probability of being unemployed, and the probability of becoming a recipient of social welfare (Borjas 1992, 1995; Bertrand et. al., 2000; Hedström and Åberg 2005; Åslund and Fredriksson 2005). Our hypothesis is however that socialinteraction effects on educational careers are double-edged in that they are conditional on the qualities of the ethnic group exerting the effect. Presumably, an ethnic group where many are doctors and lawyers will affect the children's educational ambitions differently than will an ethnic group dominated by, say, cleaners and taxi drivers.

\section{Previous studies}

Recent studies in the field of segregation have often focused the question how social segregation in schools influences the students' school performance. The main conclusion reached in Swedish studies is that the social composition of schools influences the students' school results. Students, who attend schools with high proportions of children with parents who have university degrees, and low proportions of children from families under economic hardship, perform better than children attending schools with the inverse characteristics. This is the case even when the individuals' own social background is accounted for (see: Erikson 1994; Dryler 2001; Szulkin 2005). These results correspond well with results from international (primarily U.S.) research which shows that social segregation hinders the school careers of those living in underprivileged areas (Hanushek, Kain, and Rivkin 2002; 
Robertson and Symons 2003; Willms 1986). At the same time, research shows that the variation in school results found between schools is considerably less than that within schools. This indicates that factors linked to the individual and/or family are more important for school results than factors found in the school environment. There is a related body of studies of neighborhood effects (see Garner and Raudenbush 1991; Borjas 1995; Brooks-Gunn, Duncan and Aber 1997, and reviews by Dietz 2002; Sampson, Morenoff and Gannon-Rowley 2002; Durlauf 2004), showing that "middle-class" residential areas are overall associated with better achievements of pupils, even after family-of-origin effects have been accounted for (though the causal nature of these associations is contested).

However, as pointed out by several researchers (e.g., Ellen et al. 2002), we know rather little about the effects of ethnic concentration due to recent immigration. The focus of the research (primarily carried in U.S.) has been on effects of racial segregation. The main conclusion generated by this research is that such segregation tends to depress school achievement (Boozer, Krueger, and Wolkon 1992; Grogger 1996; Cutler and Glaeser 1997; Hoxby 2000; Hanushek et al. 2002), but the empirical findings are mixed, probably due to differences in methodology and in data (Hanushek et al. 2002; Durlauf 2004). Studies of differences in school results between native-born students and those who have immigrated to that country ("first generation immigrants") show that the former on the average show better school results. The difference in school results between native-born students and children of immigrants ("second generation immigrants") is less pronounced (Portes and MacLeod 1996; Similä 1994; Vallet and Cailee 2000; see also Skolverket 2005). In an analysis of ethnic school segregation and school results in Sweden (Szulkin and Jonsson 2004), it is shown that ethnic school segregation had negative consequences for the first-generation immigrants who completed compulsory school in 1998 and in 1999. Schools with relatively many children born outside Sweden seem to constitute a problematic social environment for their students. The negative effect is most distinct among children not born in Sweden. 
To our knowledge there are only few studies that explicitly address the question how an ethnic group influence educational career in the long run. Szulkin (2006) analyzes the effects of "quantitative" and "qualitative" side of ethnic peer group on grades in compulsory school. Grönqvist (2006) explores the effects of the ethnic enclave on educational career but confines his study to the quantitative side of the enclave. Thus, our study as compared with previous studies, analyze either different outcomes or different mechanisms.

\section{The empirical estimation of neighborhood effects}

To analyse how the social environment affects individual outcomes of people entails several methodological problems (see, e.g., Dietz 2002, Manski 1993, 2000). The fact that the individuals in the different environments distinguish themselves in a number of important areas such as school performance, educational careers, labour market circumstances, criminality, and so on, may broadly be seen to be due to selectioneffects or effects generated in the neighborhoods. Selection effects arise because a prior sorting process make people in the same social environment have similar observed and unobserved individual characteristics. An example of this is that children with the same educational or class background tend to grow up in the same neighbourhoods. Because social background correlates with school performance, school performance varies between neighbourhoods. The differences between neighbourhoods with regard to future outcomes may thus be due to students' (preselection) social background, not due to (post-selection) neighbourhood effects. In order to capture the effects of the social environment, it is therefore necessary first to net out potential effects of selection.

Variation in outcomes between neighbourhoods may also come about as a consequence of processes after sorting of individuals to neighbourhoods has taken place. First, once in a neighbourhood, everyone there is subject to influence from all common characteristics of the neighbourhood. This has been variously termed in the literature: as an effect of the environment (Hedström et al. 2003), context (Manski 
2000), composition, or place (Dietz 2002). Factors common for all individuals residing in a neighbourhood may make all of them more or less likely to pursue an educational career, producing an environmental effect (using Hedström et al.'s terminology). For example, school quality, local labor market conditions and the distance to the nearest higher educational institution are factors that presumably affect all youngsters in their educational choices. Second, once in a neighbourhood there may also be social-interaction effects (also called peer-group effects). The notion underlying social-interaction effects is that individuals in the same social environment influence each other. In a neighbourhood with many individuals with high educational aspirations, the aspirational level can be raised even among those children who originally had less ambitious attitude to their education. Inversely, a negative attitude to school performance can "contaminate" those children who have been accustomed to producing good school work. ${ }^{3}$ These kinds of processes may give rise to social multiplier effects where initial small changes in behaviors through chainreactions can give rise to disproportionately large changes in behaviors at the group level.

The aspect of the neighbourhood environment analysed here is how different properties of the ethnic (or national) group within the neighbourhoods influence the individual educational career of the students within this group. There are substantial difficulties in attempting to distinguish between selection effects and effects of the neighbourhoods' resources from effects of the social interplay between the students within the neighbourhoods. However, our dataset yields good possibilities for distinguishing between social interaction effects from selection on the individual level and ethnic group level, as well as environmental neighbourhood level effects. A "naïve" analysis that does not take these problems into consideration risks resulting in upwardly biased estimates, and the effects of the social environment may in actuality

\footnotetext{
${ }^{3}$ Hedström et al. (2003:6) summarize these effects: "An environmental effect is operative if we do what we do because we are where we are. A selection effect is operative if we do what we do because we are who we are. And finally, a social-interaction effect is operative if we do what we do because others do what they do."
} 
be a result of misspecified models. On the other hand, netting out potential selection effects is likely to be accompanied by a reverse risk. Fixed effects of neighbourhoods and ethnic groups (se below) are probably also proxies for characteristics of the social environment that are actually causally connected to the future educational career (see Bertrand et al. 2000; Glaezer et al. 2007). This may lead our estimated peer groupeffects to be overly "conservative". That is, in our attempts to rule out the influence of selection effects, we probably pay a price in that we thereby run a risk of underestimating the actual significance of the childhood ethnic peer-groups for the future educational career of individuals.

As was mentioned above, our analyses are based on the assumption that individuals with the same ethnic background influence each other to a greater degree than do individuals with different ethnic backgrounds. We assume that a joint ethnic background raises the interaction probability and frequency between the individuals and that persons with the same background represent "significant others" in a social environment. ${ }^{4} \mathrm{We}$ further hypothesize that the quality and quantity of the ethnic environment are not independent entities in the creation of ethnic capital. Presumably, the higher the number of co-ethnics is, the larger the effect of quality. Our statistical model can thus be written as

$$
\begin{aligned}
& E D U C_{i j k}=\alpha+\beta_{1} Q U A L_{j k}+\beta_{2} Q U A N T_{j k}+\beta_{3}\left(Q U A L_{j k} * Q U A N T_{j k}\right) \\
& +\sum_{c=4}^{C} \beta_{c} X_{i c}+\delta_{j}+\delta_{k}+\varepsilon_{i j k}
\end{aligned}
$$

The dependent variable $E D U C$ is a measure of the highest educational level (in years) in 2003 for individual $i$ with background in country $j$ and who lived in neighbourhood $k$ during 1990 to 1995 (for details on measurement, see the methods section). The

\footnotetext{
${ }^{4}$ A limitation of the data-set/material is that the actual interaction frequency between the students is unknown. One alternative would be to collect representative interview data on the peer groups' characteristic frequency of contact between the group members and how these affect the individuals' attitudes and performance. This type of data, however, does not exist. The method used here is common in studies where conclusions about possible contextual effects are drawn from large-scale data (se Bertrand et. al., 2000; Åslund and Fredriksson 2005).
} 
central variable whose effect on educational career are analysed are the variables measuring the quality, $Q U A L_{j k}$, and quantity, $Q U A N T_{j k}$, of the ethnic group $j$ in neighborhood $k$. Because the number of coethnics for different ethnic groups as well as their characteristics varies within neighbourhoods, as well as within ethnic groups, $\beta_{1-3}$ are identifiable, and the main question being studied here is the direction and strength of these parameter estimates. The main hypothesis of this study is that the "qualitative" side of the ethnic environment matters for the future educational career, i.e. a "high quality" environment results in positive effects for its members, and a "low quality" in negative results. We also postulate the hypothesis that effects of the qualitative side of the ethnic enclave are enhanced in with the number of coethnics in the neighborhood. We do this in the belief that in neighborhoods with many coethnics, the probability is higher that social influence processes endogenously reinforce behaviors and attitudes within the group of co-ethnics, simply because competing identity-based groups of influence are relatively smaller. Whether size of the ethnic enclave per se is related to educational outcomes is an open question. If we are to expect any relationship, it should be a negative one, as one consequance of growing up in a neighborhood with a large ethnic enclanve may hamper the acquisition of host country language skills. Translating these expectations into predictions about the direction of the parameter estimates of the empirical model, we have $\beta_{1}>0, \beta_{2}<0$, and $\beta_{3}>0$.

$X_{i c}$ is control variable $c$ measuring individual or family background characteristics which there are reasons to believe play an important role for the individuals' educational performance and educational attainment. This vector encompasses the individual's sex, whether the individual is born in Sweden, the education of the parents, whether the parents receive unemployment benefits, whether parents receive social assistance, and whether the family is intact. To account for the fact that ethnic or national groups may differ with regard to educational traditions and the value attached to higher education, fixed effects $\delta_{j}$ of the individual's country of origin are also included in the model. To be able to take into account the fact that 
neighbourhoods differ systematically with regard to factors affecting the educational attainment among their inhabitants, a set of neighbourhood fixed effects $\delta_{k}$ are included in the model. Because we restrict our sample to individuals with immigrant background, all neighbourhood-specific effects on educational attainment that are common for all the immigrants in the neighbourhood are thereby accounted for. Finally, in order to analyze whether ethnic environment has direct impact on the educational career or rather is mediated through children's school success we include the grade point average of the individual in the $9^{\text {th }}$ grade.

\section{DATA AND VARIABLES}

We used a data set including information on a cohort of all students in the Swedish comprehensive schools, who attended the ninth grade in 1995 . The ninth grade is the final year of the compulsory Swedish school, and it is the year the students (normally) turn sixteen. We obtained these data from an official school register of nine-graders with information on which school they attended, and their final grades. We selected those individuals whose both parents were born abroad. We matched these data with information on (1) the students' highest education in 2003 (i.e., the year most of them turned 24), (2) their parents' country of birth, education, social assistance benefits, and unemployment benefits (3) the country of birth, and education of all adult individuals living in their residential area in the years 1990-1995. We matched the data using individual identification numbers that are used in all Swedish official individual-level registers. ${ }^{5}$ Thus, data on students' achievements are combined with information about their families and their neighbourhoods. Below, we describe how we constructed the variables in greater detail.

\footnotetext{
5 Such matching procedures are standard in Sweden, carried out by Statistics Sweden, and are considered to be overwhelmingly accurate. It should be noted that for immigrants arriving in Sweden after 1990, the matching relies on information from the annual registry of the population (RTB) and the Flergenerationsregister, to which individual-level information of parental characteristics have been added. There is no information on parents' occupation for this sub-group.
} 


\section{Dependent variable}

Our dependent variable is the highest educational level achieved in 2003. The educational levels are recoded into the number of years of education according to a Swedish standard classification (Statistics Sweden 1988): (1) incomplete compulsory education, assigned 8 years, (2) compulsory education, assigned 9 years, (3) short secondary education, assigned 11 years, (4) secondary education, assigned 12 years, (5) short postsecondary education, assigned 14 years, and (6) long tertiary education, assigned 16 years. For efficiency reasons we will treat this variable as continuous in the statistical models.

\section{The children and their parents}

Because of concerns over the protection of privacy, the variable measuring national origin is not a direct indicator of country of birth, but has been collapsed by Statistics Sweden into 28 categories, where relatively small neighboring countries and countries with language similarities have been grouped together. In the Appendix, we report this categorization. It is not ideal as some groups of countries are very heterogeneous with regard to the countries of origin, and in other respects (e.g., "Asia, other"). In a sensitivity analysis we used a reduced country of birthcategorization with only those countries where the exact country of birth is reported (see the Appendix for a description), and this did not deviate substantially from the results reported below. If the parents are born in two different "countries", the mother's is used to designate the child's background. The children of immigrants are either born abroad or in Sweden and we distinguish between these groups with the variable Born in Sweden, with value 1 if the child was born in Sweden and 0 otherwise. Adopted children are not included in the dataset. The variable Girl has value 1 if the child is a girl, 0 if the child is a boy. The variable Grade point average refers to the child's average of the grade points of all 20 subjects, given on a continuous $1-5$ scale in the final $9^{\text {th }}$ compulsory year of education. We distinguish between children living in intact and non-intact families, where we assign the value 1 
to the variable Intact family if the child is living with both biological parents in $1995 .{ }^{6}$ Furthermore, we have data on parents' level of education, unemployment experience, and experience of receiving social welfare. We measure these variables in the year when the child left compulsory school, that is, 1995. We use Years of education, highest educated parent to measure the education of the parents jointly. We assign the value 1 to the variable Parent receives social assistance if the household to which the child belongs received means-tested social assistance during 1995, otherwise 0. We assign the value 1 to the variable Parent unemployed if at least one of the parents received unemployment benefits during 1995, otherwise 0 .

\section{Neighbourhoods}

We further construct measures of characteristics of the ethnic environment on the neighbourhood level. We define a neighbourhood using Statistics Sweden's detailed geographical SAMS-codes (Small Area Marketing Statistics). These codes have been developed by Statistics Sweden in collaboration with Swedish municipalities, to designate relatively small and socially homogeneous neighborhoods. ${ }^{7}$ To avoid conflating family characteristics with neighborhood characteristics, we excluded the individual's family members from the computation of all aggregate neighborhood measures. In the analyses, we distinguish between the quantitative and qualitative side of the student's ethnic environment (cf. Bertrand et al. 2000; Åslund \& Fredriksson 2005). We also distinguish between the older (24 years + ) and younger coethnics (16 - 23 years) in the neighborhood. We define the quantitative side of the neighborhood ethnic surrounding to be the natural log of (1) the average number of

\footnotetext{
${ }^{6}$ Previous research has shown that having one Swedish-born parent and one foreign-born is indistinguishable from those having two Swedish-born parents as far as school results are concerned. The real divide is between those who do not have any Swedish-born parent (and thus a non-Swedish language as their mother tongue) and others (Similä 1994). Here, we only include those who do not have any Swedish-born parent.

${ }^{7}$ The number of SAMS-areas in Sweden is around 9,000, with an average population size of around 1,000 persons. A SAMS-area is identical to an electoral area in densely populated areas. In less densely populated areas, it is identical to a so-called NYKO-area. NYKO-areas (nyckelkodområden) are used by the municipalities for descriptive purposes, e.g., keep track of the population size of different neighborhoods.
} 
coethnics 16 - 23 years of age, and (2) the average number of coethnics 24 years + residing in the neighborhood (or neighborhoods, have they moved between them) during the years 1990-1995. ${ }^{8}$ For the younger coethnics, we define the qualitative side to be their average grades from compulsory school. For the older coethnics, we define the qualitative side to be their average years of education. In order to investigate the possibility of multiplicative effects of the quality and quantity of the ethnic environment, we created interaction terms of these. After exclusion of 2,638 individuals with missing values on any of the variables, most commonly because no younger coethnics resided in the neighborhood, we had a sample of 6,560 individuals. We compared the highest education at age 24 for the excluded cases with those included, and the excluded cases had, on average, .3 years more education, suggesting that the immigrant children who are included in our analytical sample fared somewhat worse educationally than those immigrant children who grew up in neighborhoods without non-family coethnics. ${ }^{9}$ Descriptive statistics are presented in Table 1.

Table 1 about here

\section{RESULTS}

In Table 2 we report the results from six models, where the effects of ethnic environment in the neighbourhood on highest educational level achieved eight years after compulsory school are estimated. The first model in Table 2 is the "naïve model" assuming that the quantitative and qualitative sides of the ethnic environment

\footnotetext{
${ }^{8}$ Most empirical research on neighborhood effects uses data at a single point in time. As noted by Ellen and Turner (1997), this approach poses at least two potential problems: (1) measurement error because of random between-year fluctuations in neighborhood characteristics, and (2) insensitivity to the length of time an individual has been exposed to a neighborhood environment. In our study, we try to circumvent these problems by making use of six consecutive yearly observations of neighborhood membership during the period the children are 10-16 years of age.

${ }^{9}$ We compared the figures in the table to those for nonimmigrants in the same cohort, and our sample of immigrants has, in comparison, lower grades, and lower education in 2003. Their parents have lower education, are to a higher extent unemployed, and are to a higher extent dependent on social assistance, compared with the parents of nonimmigrants in the same cohort (results not shown).
} 
in neighborhoods are the only factors influencing the future educational career of the children. In Model 2, the effects of ethnic environment are estimated controlling for individual-level variables. In Model 3 the fixed effects for neighborhoods and ethnic groups are added. For these fixed effects, we defined the neighborhood of an individual to be his or her modal residential neighborhood during the period $1990-$ 1995. In Model 4, in order to analyze how much of the neighborhood effect is mediated by success in compulsory school we add the grade point average from compulsory school. Finally, in Model 5 and 6 the analyses from Model 4 and 5 are rerun on a sample restricted to individuals who did not move between neighborhoods during $1990-1995$.

Table 2 about here

The question asked in the first analysis is whether there is a correlation between the number of years of education achieved by the individual eight years after compulsory school and the character of the ethnic environment of the childhood neighborhoods. Model 1 shows that individuals growing up in neighborhoods with relatively high number of coethnics (both young and adult) have lower performance, in terms of educational careers, than individuals who lived in neighborhoods with relatively few coethnics. The main effect of the qualitative side of the ethnic environment is relatively weak and insignificant. However, the joint effect of quantitative and qualitative side of the ethnic environment (the interaction term) is positive and significant. Individuals brought up in neighborhoods with high numbers of coethnics who are well educated (the adult group) or reach high levels of achievement in school (the young group) are characterized by relatively high levels of educational attainment. A joint analysis of the effects of quantitative and qualitative sides of ethnic environment are presented in Figure 1 and Figure 2. We restrict our predictions to actually observed combinations of quality and quantity. They indicate that there is a critical average level of grades/educational level which conditions for 
weather the increase of number of coethnics is negative or positive for the future educational career. As can be seen in Figure 1, for individuals growing up in neighborhoods where young coethnics have average grades equal to or below 3 , the increase in number of coethnics is negative for individuals' educational attainment. If the average level of degrees is equal to or higher than 3.2 the increase in number of coethnics is positive for future educational career. Similarly, as can be seen in Figure 2 , there appears to be a critical level of about 14 years of education above which increasing numbers of coethnics have a positive impact on the future educational career. The individuals residing in these kinds of neighborhoods constiture a minority of the immigrant children in our sample. 23 percent grew up in neighborhoods where the coethnic youth had average grades above 3.2, and only 1.3 percent grew up in neigborhoods where adult coethnics had an average education of 14 years or more. It is also worth mentioning that Model 1 accounts only for 3.5 percent of the variance in individuals' years of education, indicating that ethnic environment is not the major source of variation in educational careers of young people of immigrant origin in Sweden.

Figure 1 and 2 about here

In Model 2 we add controls for individual-level variables and family background. The idea behind this model is that endogeneity causes an upward bias in estimates of neighborhood effects in Model 1. Families group themselves in residential areas and children from relatively resourceful families have high probabilities to end up in resourceful social environments. The opposite can be assumed to be the case for children from families with relatively resources. Thus, it can be expected that controls for family background will lower the association between ethnic environment and educational career of individuals studied. The results from the analysis in Model 2 do not unambiguously confirm this presumption. Even 
though the associations between our two measures of quantitative side of neighborhood and the educational careers of individuals studied are somewhat attenuated, the joint effect of quantitative and qualitative side remains almost unchanged.

Thus, the results still indicate that there are some negative externalities of the quantitative side of the ethnic environment and some positive externalities of the joint measures of quantity and quality of the ethnic environment for the individual educational careers. Adding measures of individual and family background substantially increase the variance explained. Model 2 accounts for 12 percent of the variance in individuals' years of education.

As mentioned before, our estimates of ethnic surroundings may be biased due to several processes: population sorting (or unobserved neighbourhood heterogeneity), environmental characteristics that are common for a neighbourhood that influence all young people and their long-term aspirations and educational careers. To distinguish effects of the ethnic environment from these alternative sources of influence entails considerable methodological problems. In the analysis above, we have used a relatively "rich" individual-level model. However, we cannot claim that all neighborhood heterogeneity is controlled for in this model. For instance, there may be unmeasured variables which are related to immigrant children's' educational careers but unrelated to the measures of social background in the model. If some families with relatively low human capital and/or social problems are characterized by high levels of educational aspirations for their children they may move to neighborhoods with "positive" social characteristics. In this case the estimates of ethnic environment in Model 2 may be upwardly biased. Introducing neighbourhood-dummies in Model 3 solves this problem. The remaining effects of ethnic environment in a model with neighbourhood-dummies are "cleansed" for the fact that what we here call resourceful ethnic environment are more common in neighborhoods where the social composition of native children is also "positive" for school results and future educational careers. Introducing dummy-variables for ethnic 
groups in a similar way solves the problem that ethnic environments simply may mirror varying educational traditions in immigrant groups from different countries rather than the effects of social interaction in an ethnic group in a neighborhood.

Model 3 shows the results from the analysis of the effects of ethnic environment taking into consideration these extensive controls for individual-, ethnic group- and neighbourhood-level variables. As can be seen in the table, the effects of ethnic environment are modified with this model specification. The estimates indicating the effects of quantitative and qualitative characteristics of young coethnics in a neighborhood (and their joint effect) are somewhat stronger than the corresponding estimates in the previous model. However, within-neighborhood and within-ethnic group parameters are estimated with lower precision, higher standard errors, and their estimates turn insignificantly different from zero. A cautious interpretation is that growing up in a neighborhood with relatively many young coethnics, to some extent, impedes the educational career. The joint effect of quantitative and qualitative sides of ethnic environment indicates that sharing an ethnic environment with many young people of same origin who are successful in school creates favorable conditions for future educational career. The estimates indicating the characteristics of adult coethnics in the same neighborhood are all attenuated towards zero. Thus, the characteristics of the younger group of coethnics seem to play role in the process of educational attainment, the characteristics of the elder group are more or less unrelated to the future educational progress of young individuals'. Adding dummies for neighborhoods and ethnic groups increase the variance explained. Model 3 accounts for 15.5 percent of the variance in individuals' years of education.

In Model 4 we add average grades from the ninth grade into the equation. The main result of this analysis is that all neighborhood effects are insignificantly different from zero. Parameters indicating the effects of characteristics of young coethnics in the neighborhood are attenuated to zero, suggesting that their possible effects are mediated by differences in success in compulsory school. It is worth 
mentioning that the variance explained in Model 4 increases substantially. In this model about 44 percent of individuals' years of education are accounted for, indicating that the grades from compulsory school is a very important predictor of future educational career.

A problem with many neighborhood effects studies is that neighborhood affiliation is measured for a very limited period of time. Short-term fluctuation and measurement error of neighborhood affiliation then attenuate any true effect of neighborhood. We tried to circumvent this problem by extending the period of time when we measure the neighborhood characterisics to 1990 - 1995. Still, one may argue that children who move during the period we measure their neighborhood affiliation should be less affected by the coethnics living there, simply because they fail to get to know the people living there. If this is a real problem, our estimates of neighborhood effects would be biased downwards. To assess the magnitude of this problem, we restricted the sample to include only those children who did not move between neighborhoods during the period in question, and reestimated model 3 and 4. By restricting the sample to this group, it turns out that the coefficients associated with the young ethnic surrounding in the childhood neighborhood increase in both size and significance (Model 4). However, the parameter estimates associated with the adult coethnic surrounding remains low and insignificant. There are, in other words, the characteristics of young coethnics growing up in same neighbourhood that seem to be important for the future educational success in this group. The main effects of quantitative and qualitative sides of ethnic environment aged $16-23$ are negative and their joint effect is positive. The estimated parameters of these effects are much stronger than they were in our naïve model (Model 1). Thus, growing up in a large coethnic community (of young people) seems to be detrimental for the future educational attainment. This effect is, however, conditional on the average school success of the group. Similarly to what has been shown in Figure 1, a joint analysis of the effects of quantitative and qualitative sides of ethnic environment presented in Figure 3 indicates that there is a critical average level of grades which conditions for 
weather the increase of number of coethnics is negative or positive for the future educational career. As can be seen in the figure for ethnic groups with average grades equal to or below 3 the increase in number of coethnics is negative for individuals' educational attainment. If the average level of grades is equal to or higher than 3.3 the increase in number of coethnics is positive for future educational career. To put this number into perspective, we calculated the percentile rank it represented in the distribution of average grades in the neighborhoods. It turned out that a relatively small minority, just 17 percent, of the individuals in our sample grew up in neighborhoods where the young coethnics had an average grade level above 3.3. Condidering the joint effect of quality and quantity, effects are moderate, normally below a 1-year difference in education, at levels of quality close to the average, but somewhat larger at extreme values of quality. Comparing the predicted outcomes of an individual in an environment with 10 coethnics with very low average grades, equal to 1 , to that of an individual with 50 coethnics with the same level of average grades, gives a predicted difference of 1.4 years of education.

Figure 3 about here

Adding average grades from the ninth grade into the equation (Model 6) indicates that the results in Model 5 are fully mediated by success in the compulsory school. That is, all of the effect of the quality and quantity of the ethnic environment in childhood neighborhood is chanelled through grades, over and above which these characteristics of the ethnic group do not matter much.

To sum up, the pattern of an increasing effect of coethnic characteristics with an increasing quantity of these coethnics is consistent with our theoretical expectations, that the joint effect of these factors sum to more than zero. The neighborhood effects that we were able to identify were fully accountable by final school results in $9^{\text {th }}$ grade. 


\section{CONCLUDING DISCUSSION}

The central premise behind the analyses in this study is that a shared ethnic/national background facilitates social interaction between these individuals, and that ethnic enclaves in neighborhoods constitute important socialization arenas for the children growing up there. Among other things, interaction within an ethnic group in a neighborhood may create and uphold norms about the value of education. To be able to formulate hypotheses on the effects of growing up in an ethnic enclave, we therefore need information on the social characteristics of the individuals making it up. In the empirical analysis we have distinguished between the quantity and quality of ethnic groups within neighborhoods. The quantitative side is the number of coethnics living in the neighborhood. The qualitative side measures the educational resources of the ethnic group in the neighborhood. We expected an environment with many coethnics and relatively limited educational resources to affect educational careers negatively, and an environment with many coethnics and relatively high educational resources to affect educational careers positively.

We used a dataset comprising a total cohort of immigrant children who graduated compulsory school in 1995 . We followed these children retrospectively to 1990 to measure neighborhood characteristics during late childhood, and prospectively to 2003 to measure their educational attainment thus far. Our empirical analysis showed that growing up in an ethnic enclave is harmful if children for an extended period of time grow up in a neighborhood where the average level of education in the enclave is medium to low. This negative effect is enhanced with the number of coethnics in the neighborhood. The effect of the neighborhood is however fully captured by success in compulsory school. That is, children who grow up these neighborhoods underachieve in compulsory school, and therefore do not continue to higher education to the same extent as children growing up elsewhere. This result suggests that the effect of the ethnic surrounding on later educational attainment build on school results achieved in childhood (cf. Heckman 2006). 
Thus, the downside of the ethnic enclave is visible in our analyses. We also expected that relatively large and resourceful ethnic environments would create an educational advantage for its inhabitants. We do find such a positive effect, but it pertains to a small minority of immigrants who grew up in neighborhoods with educationally resourceful coethnics.

Is it good or bad to grow up in an ethnic enclave? We conclude that for the educational outcome studied in this paper, it is, as a rule, bad. Immigrant children who grow up in neighborhoods with no coethnics fare better than those grow up in neighborhoods with coethnics. For the overwhelming majority of immigrant children with coethnics in their neighborhood, the larger the coethnic community in their neighborhood, the worse they fare in school, and as a consequence, the worse they fare educationally later in life. Only a minority of immigrant children who grow up in neighborhoods with educationally very successful coethnics benefit from being surrounded by a high concentration of coethnics.

Are the results of this study unique to the Swedish context? We would argue that our estimates, in an international comparison, produce lower bound estimates of neighbourhood effects. Inequality of educational opportunity (and social inequality in general) is relatively limited in Sweden (Björklund et al. 2003, Erikson and Jonsson 1996:57). The variation in school quality between neighborhoods is fairly low, and higher education is heavily subsidized. The role of ethnic isolation resulting from residential segregation in the process through which social advantage of parents translates to educational career of children therefore should be rather small. Still, our estimates of the effect of growing up in a low-resource ethnic enclave are nontrivial, suggesting the salience of ethnic enclaves to be rather high in countries and institutional contexts where there is more ghettoisation, more variation in standards across neighborhoods, and where there are higher costs associated with higher education. 


\section{List of references}

Bertrand M., Luttmer, E. F. \& S. Mullainathan. 2000. "Network effects and Welfare Cultures". The Quarterly Journal of Economics, vol. 115, 1019-1055.

Biterman, D. \& Franzén, E. 2007. "Residential segregation (Chapter 6)" in (Social report 2006. The National Report on Social Conditions in Sweden) International Journal of Social Welfare, 16, July Supplement 2007

Borjas G. J. 1992. "Ethnic Capital and Intergenerational Mobility". The Quarterly Journal of Economics, February, vol. 107, 123-150.

Borjas, G. J. 1995. "Ethnicity, Neighbourhoods, and Human Capital Externalities". American Economic Review, vol. 85, 365-390.

Boozer, Michael A., Alan B. Krueger, \& Shari Wolkon. 1992. "Race and school quality since Brown v. Board of Education." Brooking Papers on Economic Activity: Microeconomics: 1992, 269-326.

Brooks-Gunn, Jeanne, Greg J. Duncan, and J. Lawrence Aber, eds. 1997. Neighborhood Poverty. Volume 1. Context and consequences for children. New York: Russell Sage.

Byrne, D. 1971. The Attraction Paradigm. New York: Academic Press.

Chiswick, B. R. 1978. "The Effect of Americanization on the Earnings of Foreignborn Men". Journal of Political Economy vol. 86, 897-921.

Coleman, J. S. 1988. "Social Capital in the Creation of Human Capital". American Journal of Sociology vol. 94 Supplement, 95-120.

Cutler, D. M. \& E. L. Glaeser. 1997. "Are Ghettos Good or Bad?”. Quarterly Journal of Economics vol. CXII, 827-872.

Cutler, D. M., Glaeser, E. L. \& J. L. Vigdor. 2007. When Are Ghettos Bad? Lessons from Immigrant Segregation in the United States. NBER Working Paper 13082. Cambridge, MA: National Bureau of Economic Research.

Dietz, R. D. 2002. "The estimation of neighborhood effects in the social sciences: An interdisciplinary approach", Social Science Research vol. 31, 539-575.

Dryler, H. 2001. "Etnisk segregation i skolan”, pp. 319-355 in SOU 2001:57. Stockholm: Fritzes.

Durlauf, S. N. 2004. "Neighborhood Effects", pp. 2173 - 2242 in Henderson, J. V., \& Thisse, J.-F. (eds), Handbook of Regional and Urban Economics, Vol. 4. Amsterdam: Elsevier Science.

Ellen, I. G. \& M. A. Turner. 1997. Does Neighborhood Matter? Assessing Recent Evidence. Housing Policy Debate, vol. 8, 833-866. 
Ellen, I. G., O’Regan, K., Schwartz, A. E. \& L. Stiefel. 2002. "Immigrant Children and New York City Schools: Segregation and Its Consequences." BrookingWharton Papers on Urban Affairs, 183-214.

Erikson, R. 1994. "Spelar valet av skola någon roll?", pp. 132-71 in R. Erikson \& J.O. Jonsson (eds), Sorteringen i skolan. Stockholm: Carlssons.

Garner, C.L. \& Raudenbush, S.W. 1991. "Neighborhood Effects on Educational Attainment: A Multilevel Analysis". Sociology of Education vol. 64, pp. 251262.

Gordon M. M. 1964. Assimilation in American Life: The Role of Race, Religion, and National Origins. New York: Oxford University Press.

Grogger, J. T. 1996. "Does school quality explain the recent black/white trend?" Journal of Labor Economics vol. 14, 231-53.

Grönqvist, H. 2006. Ethnic Enclaves and the Attainments of Immigrant Children. European Sociological Review, vol. 22, 369-382

Hanushek, E. A., J. F. Kain, \& S. G. Rivkin. 2002. "New Evidence about Brown vs. Board of Education: The Complex Effects of School Racial Composition on Achievement", Working Paper 8741, National Bureau of Economic Research.

Heckman, J. J. 2006. "Skill Formation and the Economics of Investing in Disadvantaged Children", Science, vol. 312. 1900-1902.

Hedström, P., Kolm, A.-S. \& Y. Åberg. 2003. "Social Interactions and Unemployment." IFAU Working Paper 2003:15.

Hedström, P. \& Y. Åberg. 2005. "Quantitative research, agent-based modelling and theories of the social", pp. 114-144 in Hedström, P. Dissecting the Social. On the Principles of Analytical Sociology, Cambridge, UK: Cambridge University Press.

Hoxby, C. M. 2000. "Peer effects in the classroom: Learning from gender and race variation." Working Paper 7867, National Bureau of Economic Research.

Lincoln, J. R., \& J. Miller 1979. "Work and Friendship Ties in Organizations: A Comparative Analysis of Relational Networks." Administrative Science Quarterly, vol. 24, 181-199.

Manski, C. F. 1993. "Identification of endogenous social effects: the reflection problem." Review of Economic Studies vol. 60, 531-542.

Manski, C. F. 2000. "Economic analysis of social interactions." Journal of Economic Perspectives vol. 14, 115-136.

McPherson, J. M., \& L. Smith-Lovin. 1987. "Homophily in Voluntary Organizations: Status Distance and the Composition of Face-to-Face Groups." American Sociological Review, vol. 52, 370-379. 
McPherson, M., Smith-Lovin, L., \& J. M. Cook. 2001. "Birds of a Feather: Homophily in Social Networks." Annual Review of Sociology, vol. 27, 415-444.

Morgan, S.L. \& A. B. Sørensen. 1999. "Parental Networks, Social Closure, and Mathematical Learning: A Test of Coleman's Social Capital Explanation of School Effects". American Sociological Review, vol. 64, 661-681.

Pfeffer, J. 1989. "A Political Perspective on Careers: Interests, Networks, and Environments." pp. 380-396 in M. B. Arthur, D. T. Hall \& B. S. Lawrence (eds), Handbook of Career Theory. Cambridge: Cambridge University Press.

Portes, A. 1995. "Children of Immigrants: Segmented Assimilation and its Determinants", pp. 248-280 in Portes, A. (ed), The Economic Sociology of Immigration: Essays on Networks, Ethnicity, and Entrepreneurship. New York: Russel Sage Foundation.

Portes, Alejandro \& D. MacLeod. 1996. "Educational Progress of Children of Immigrants: The Roles of Class, Ethnicity, and School Context", Sociology of Education, vol. 69, 255-275.

Robertson, D., \& Symons, J. 2003. "Self-selection in the state school system." Education Economics, vol. 11, 259-273.

Reskin, B. F., D. M. McBrier, \& J. A. Kmec. 1999. "The Determinants and Consequences of Workplace Sex and Race Composition." Annual Review of Sociology, vol. 25, 335-361.

Robertson, D., \& J. Symons. 2003. "Self-selection in the state school system." Education Economics vol. 11, 259-273.

Sampson, R. J, Morenoff, J. D. \& Gannon-Rowley, T. 2002. "Assessing "Neighborhood Effects": Social Processes and New Directions in Research", Annual Review of Sociology, vol. 28, 443-78.

Similä, M. 1994. “Andra generationens invandrare i den svenska skolan”, pp. 226-63 in R. Erikson and J. O. Jonsson (eds), Sorteringen $i$ skolan. Stockholm: Carlsson.

Skolverket. 2005. Elever med utländsk bakgrund: En sammanfattande bild.

Szulkin R., 2005. "Hur stora är chanserna till en utbildningskarriär?”. pp. 121-144 in Molander, P. \& K. Stigmark (eds), Självstyrelse, likvärdighet, effektivitet: Målkonflikter $i$ den offentliga sektorn. Stockholm: Riksbankens Jubileumsfond $\&$ Gidlunds förlag.

Szulkin R. \& J. O. Jonsson. 2004. "Ethnic segregation and educational outcomes in Swedish comprehensive schools: A multilevel analysis" Manuscript.

Vallet, L.-A. \& J. P. Caille. 2000. "Migration and integration in France. Academic careers of immigrants' children in lower and upper secondary school", Paper presented at the ISA RC28 conference in Libourne, France. 
Willms, Douglas J. 1986. "Social Class Segregation and its Relationship to Pupils' Examination Results in Scotland." American Sociological Review vol. 51, 224241.

Zhou, M. 1997. "Growing up American: The Challange Confronting Immigrant Children and Children of Immigrants". Annual Review of Sociology vol. 23, 6395.

Zhou, M. \& C. L. Bankston. 1998. Growing up American: How Vietnamese Children Adapt to Life in the United States. New York: Russell Sage Foundation.

Åslund, O. \& P. Fredriksson. 2005. "Ethnic Enclaves and Welfare Cultures - Quasi Experimental Evidence". Center for Economic Studies \& Ifo Institute for Economic Research CESifo. Working paper No. 1430. 


\section{Table 1: Descriptives}

\begin{tabular}{|c|c|c|c|c|c|}
\hline Variable & Obs & Mean & StdDev & Min & $\operatorname{Max}$ \\
\hline Years of education in 2003 (dependent variable) & 6560 & 11.970 & 2.154 & 8 & 16 \\
\hline Years of education, highest educated parent & 6560 & 11.277 & 2.704 & 8 & 20 \\
\hline Parent unemployed & 6560 & .424 & & 0 & 1 \\
\hline Parent receives social assistance & 6560 & .454 & & 0 & 1 \\
\hline Intact family & 6560 & 686 & & 0 & 1 \\
\hline Girl & 6560 & .479 & & 0 & 1 \\
\hline Born in Sweden & 6560 & .530 & & 0 & 1 \\
\hline Grade point average, $9^{\text {th }}$ grade & 6560 & 2.928 & .782 & 1 & 4.9 \\
\hline \multicolumn{6}{|l|}{ Quantitative aspect of neighbourhood coethnics 1990-1995: } \\
\hline $\begin{array}{l}\ln (\# \text { of individuals with the same ethnicity, aged } 16-23 \text { years, in the } \\
\text { neighbourhood }+1 \text { ) }\end{array}$ & 6560 & 2.040 & 1.047 & .693 & 5.609 \\
\hline $\begin{array}{l}\ln (\# \text { of individuals with the same ethnicity, aged } 24 \text { years or more, in } \\
\text { the neighbourhood }+1)\end{array}$ & 6560 & 4.000 & 1.326 & .693 & 7.435 \\
\hline \multicolumn{6}{|l|}{ Qualitative aspect of neighbourhood coethnics 1990-1995: } \\
\hline Average grades in school, coethnics aged $16-23$ years & 6560 & 2.862 & .545 & 0. & 4.8 \\
\hline Highest education, years, coethnics aged 24 years or more & 6560 & 10.665 & 1.216 & 8 & 20 \\
\hline
\end{tabular}


Table 2. Regression analyses of years of education in 2003 after 9th grade completion in 1995, on indicators of the neighbourhood ethnic environment during childhood. Individuals with both parents born outside of Sweden.

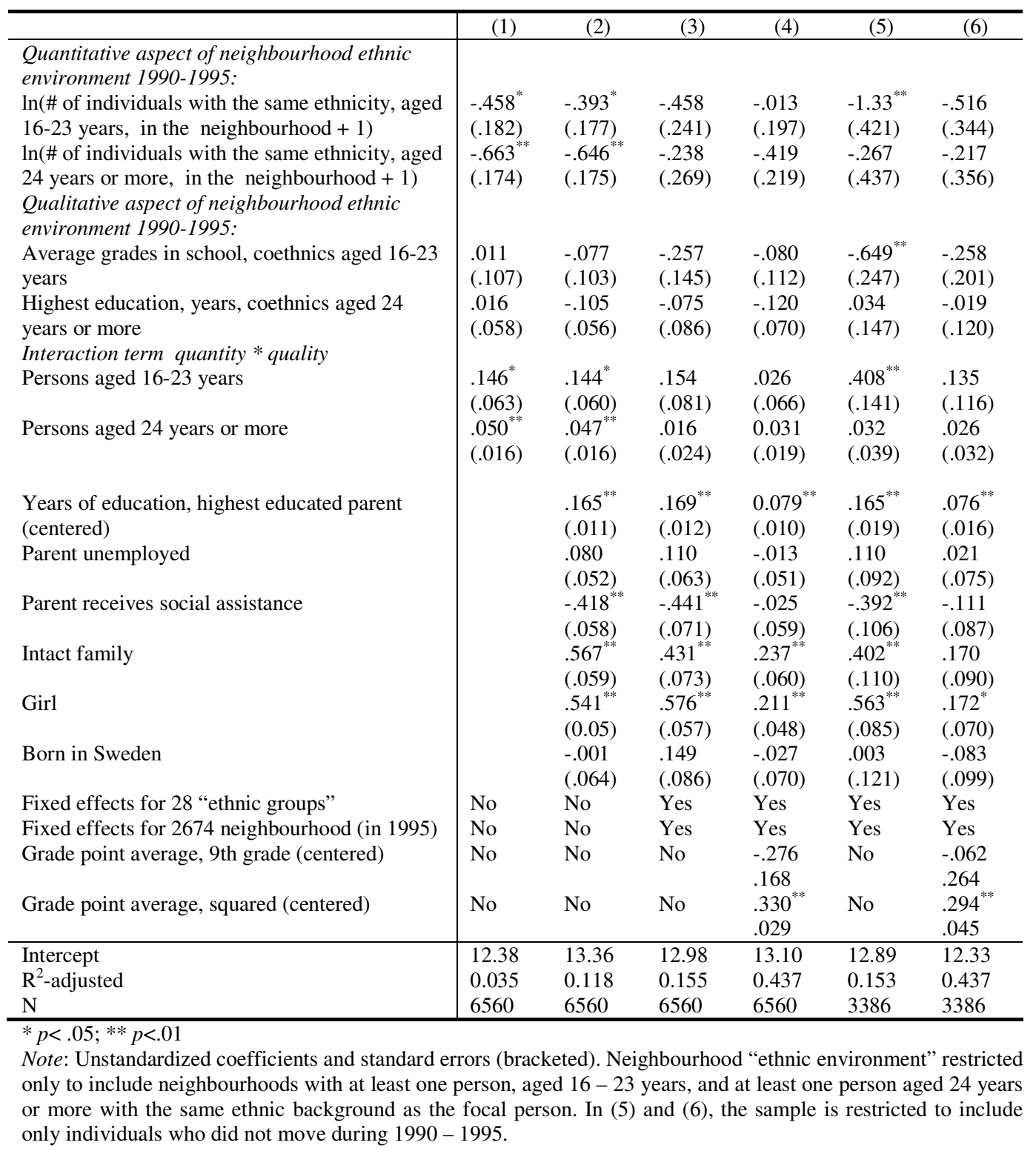


Figure 1: Predicted years of education, for different levels of quantity and quality (average grades) of the coethnic surrounding, aged 16-23 years, of childhood neighborhood, using coefficients from column 1, Table 2 (i.e. no controls).

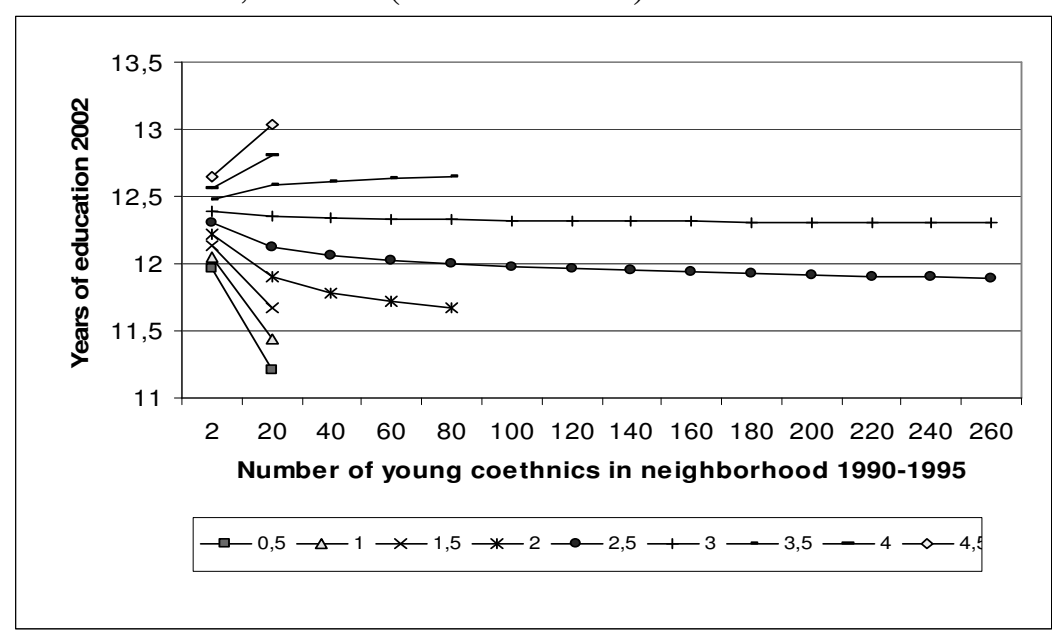

Figure 2: Predicted years of education, for different levels of quantity and quality (average years of education) of the coethnic surrounding, aged 24 years+, of childhood neighborhood, using coefficients are from column 1, Table 2 (i.e., no controls).

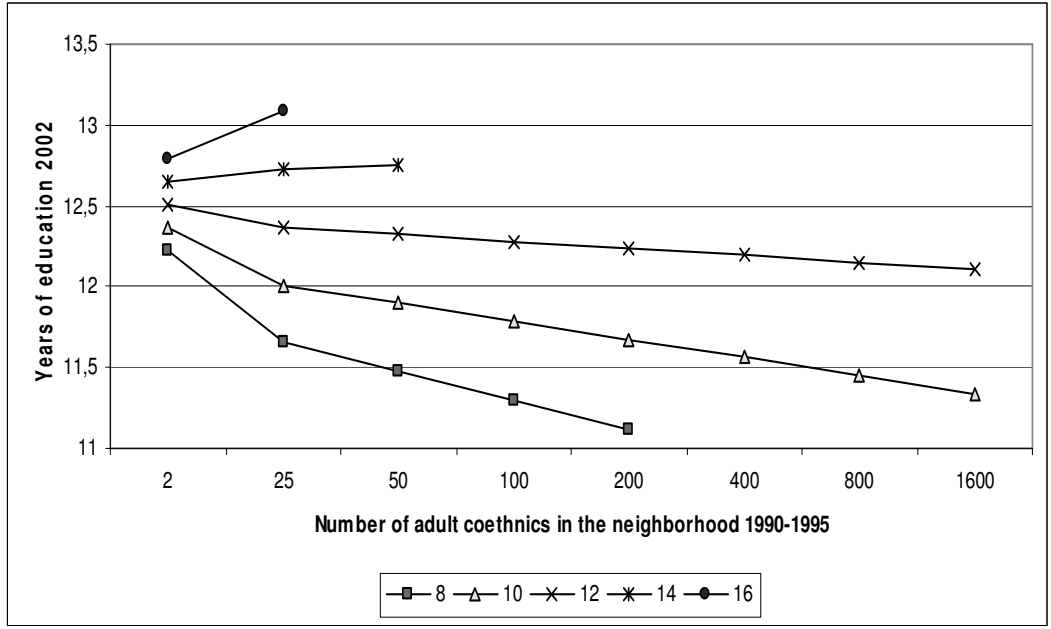


Figure 3: Predicted years of education, for different levels of quantity and quality (average grades) of the coethnic surrounding, aged 16-23 years, of childhood neighborhood, using coefficients from column 5, Table 2 .

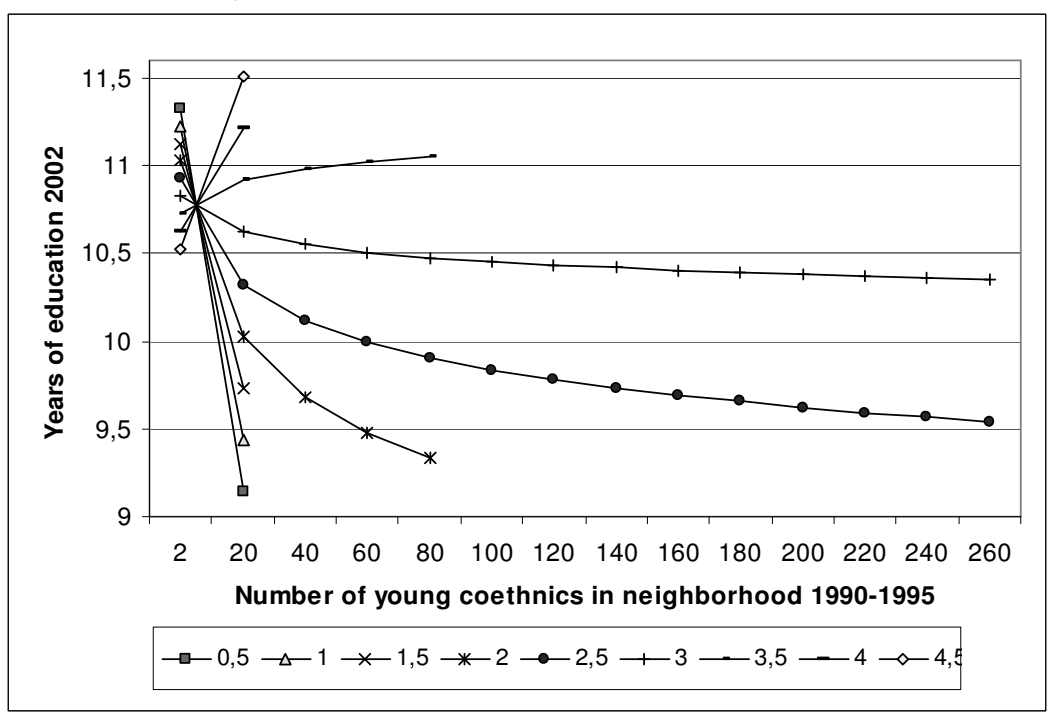




\section{Appendix: origin country grouping}

Alternative origin country grouping, exhibiting less within-group heterogeneity, in bold.

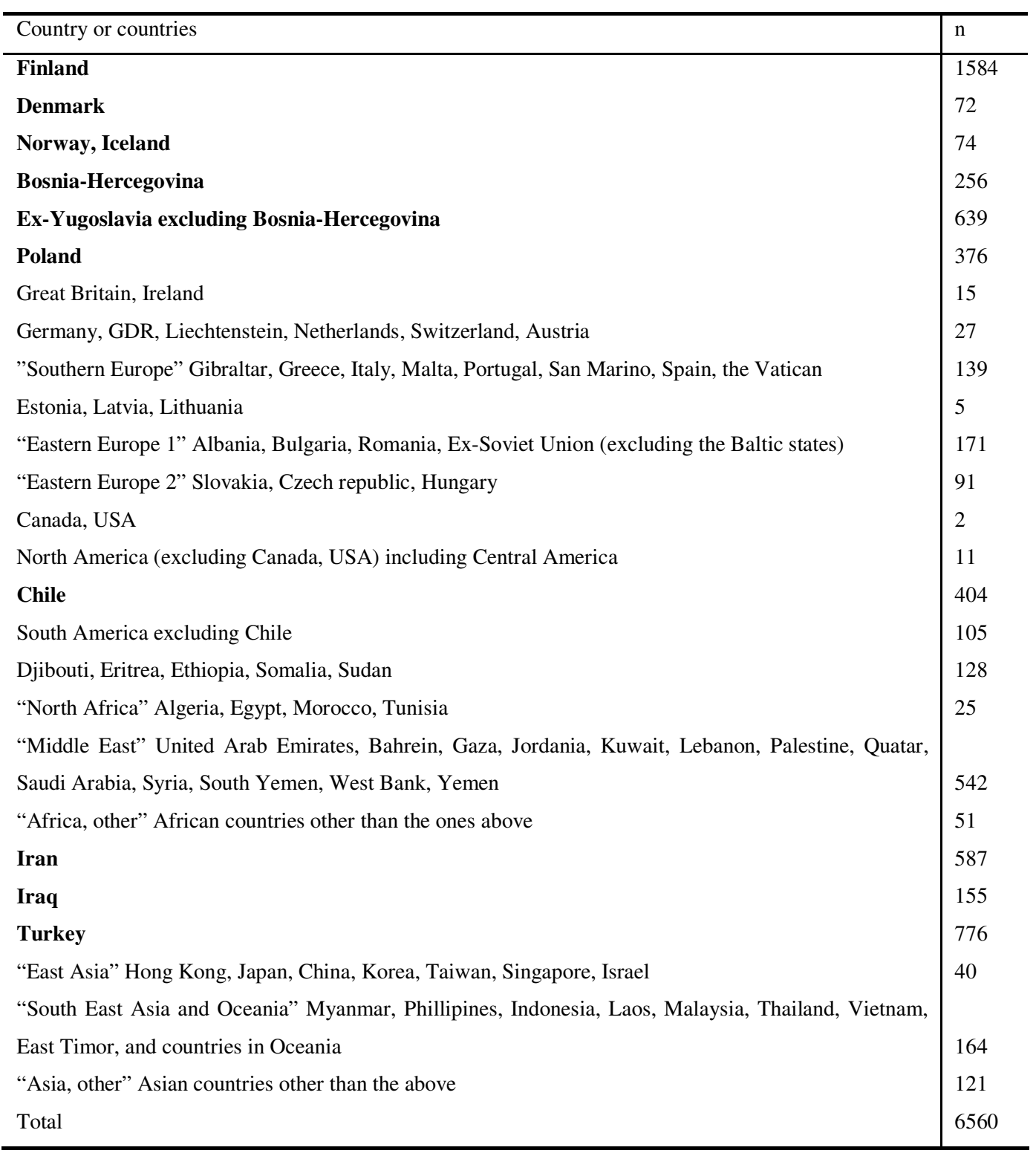


SULCIS is a multi-disciplinary research center focusing on migration and integration funded by a Linnaeus Grant from the Swedish Research Council (VR). SULCIS consists of affiliated researchers at the Department of Criminology, the Department of Economics, the Department of Human Geography, the Department of Sociology and the Swedish Institute for Social Research (SOFI). For more information, see our website: $\underline{w w w . s u . s e / s u l c i s}$

\section{SULCIS Working Paper Series}

2007:1 Arai, M \& Skogman Thoursie, P., "Giving Up Foreign Names: An empirical Examination of Surname Change and Earnings"

2007:2 Szulkin, R. \& Jonsson, J.O., "Immigration, Ethnic Segregation and Educational Outcomes: A Multilevel Analysis of Swedish Comprehensive Schools"

2007:3 Nekby, L. \& Özcan, G., "Do Domestic Educations Even Out the Playing Field? Ethnic Labor Market Gaps in Sweden"

2007:4 Nekby, L. \& Rödin, M., "Acculturation Identity and Labor Market Outcomes"

2007:5 Lundborg, P., "Assimilation in Sweden: Wages, Employment and Work Income"

2007:6 Nekby, L., Rödin, M. \& Özcan, G., "Acculturation Identity and Educational Attainmnet"

2007:7 Bursell, M., "What's in a name? A field experiment test for the existence of ethnic discrimination in the hiring process"

2007:8 Bygren, M. \& Szulkin, R., "Ethnic Environment during Childhood and the Educational Attainment of Immigrant Children in Sweden" 